\title{
Relação intergeracional e aprendizagem docente: elementos para rediscutir a formação de professores
}

\author{
Flavia Medeiros Sarti \\ Michelle Cristina Bueno \\ Universidade Estadual Paulista
}

\section{Resumo}

artigo discute aspectos relativos à aprendizagem docente, compreendida como processo de socialização profissional. Destaca a importância das relações intergeracionais estabelecidas entre professores iniciantes (entre os quais, os estudantes das licenciaturas durante os estágios) e professores experientes em situações de ensino. Parte de resultados obtidos no âmbito de uma investigação qualitativa, que elegeu como referencial empírico o estágio supervisionado em um curso de Pedagogia. A coleta de dados ocorreu por meio de observações (com o recurso de videogravação) das aulas de uma estagiária do curso e de entrevistas semi-estruturadas (recorrendo à videoconfrontação) realizadas com a estagiária e a professora supervisora do estágio. Os dados foram analisados no que se refere ao seu conteúdo, a partir de categorias teóricas desenvolvidas por autores ligados à didática profissional e por autores que, sob outras perspectivas, também discutem o processo de desenvolvimento profissional docente. As discussões propostas ressaltam importantes lacunas no modelo de formação inicial vigente, no que se refere a sua dimensão iniciática, como parte de um processo mais amplo de socialização profissional.

Palavras-chave: Desenvolvimento profissional docente. Videoconfrontação. Didática profissional.

\section{Intergenerational relationship and teacher learning: elements for rediscussing teacher education}

\section{Abstract}

This article discusses teacher learning as a process of professional socialization, highlighting the importance of intergenerational relationships between new teachers (including undergraduate students during trainees) and senior teachers in teaching situations. It is based on the results obtained in a qualitative research that has as the empirical reference a supervised trainee in a Pedagogy course. Data collection were done through observations (with video recording) of the trainee's classes and semi-structured interviews (using videoconfrontation) performed with the trainee and the teacher responsible for the 
Relação intergeracional e aprendizagem docente: elementos para rediscutir a formação de professores

traineeship. We analyzed these data in terms of their content, through theoretical categories developed by authors who are related to professional didactics and others who, from different perspectives, also discuss the process of professional teacher development. The discussions emphasize important gaps in the current initial training model, in terms of its initiatory dimension, as part of a broader process of professional socialization.

Keywords: Teacher professional development. Videoconfrontation. Professional didactics.

\section{Relación intergeneracional y aprendizaje docente: elementos para rediscutir la formación de profesores}

\section{Resumen}

El artículo discute aspectos relativos al aprendizaje docente, comprendido como proceso de socialización profesional. Destaca la importancia de las relaciones intergeneracionales establecidas entre profesores iniciantes (entre ellos, los estudiantes de las licenciaturas durante sus prácticas) y profesores con experiencia en situaciones de enseñanza. Tiene como punto de partida los resultados obtenidos en el ámbito de una investigación cualitativa, que eligió como referencial empírico las prácticas supervisadas en un curso de Pedagogía. La recolección de datos ocurrió por medio de observaciones (con el recurso de la videograbación) de las clases de una practicante del curso y de entrevistas semiestructuradas (recurriendo a la vídeo confrontación) realizadas con la practicante y la profesora supervisora de las prácticas. Los datos se analizaron en cuanto a su contenido, a partir de categorías teóricas desarrolladas por autores relacionados a la didáctica profesional y por autores que, bajo otras perspectivas, también discuten el proceso de desenvolvimiento profesional docente. Las discusiones propuestas resaltan importantes lagunas en el modelo de formación inicial vigente, en lo que se refiere a su dimensión iniciática, como parte de un proceso más amplio de socialización profesional.

Palabras clave: Desenvolvimiento profesional docente. Vídeo confrontación. Didáctica profesional.

\section{Introdução}

As discussões apresentadas neste artigo são frutos de parte de pesquisa reO abandono precoce da profissão docente impõe-se como um importante desafio cuja recorrência atualmente vem sendo associada por diversos pesquisadores ao "choque de realidade" ou "choque de transição" (VEENMAN, 1984, p. 143) comumente enfrentado por professores iniciantes 
em suas primeiras investidas no magistério (CANCHERINI, 2009; MARCELO, 1999; MARIANO, 2006; SOARES, 2004; TARDIF, 2010). Sentimentos de insegurança e frustrações diversas caracterizam o ingresso no magistério para muitos jovens professores, que se ressentem da formação inicial que receberam, considerando-a incipiente para o enfretamento dos múltiplos desafios impostos pela docência cotidiana a um novato na profissão (COSTA FILHO, 2014 ; FERREIRA, 2005; PIMENTA, 2007; RODRIGUES, 2010 ; SIMON, 20131. Esse desencontro entre formação e contexto de atuação profissional produz o referido efeito de choque, indicando falhas no processo de iniciação dos sujeitos no magistério.

Embora o termo iniciante seja geralmente empregado no caso dos professores que ingressam na carreira docente, é possível considerá-lo adequado para designar os estudantes dos cursos de licenciatura que, em muitos aspectos, estão ou deveriam estar sendo iniciados no magistério. Em algumas propostas de estágio supervisionado, esses estudantes têm oportunidades de experimentar certos processos envolvidos na "exploração" do ofício (HUBERMAN, 1992). Nesses casos, os professores que os recebem em suas classes são chamados a desempenhar o papel de iniciadores de uma nova geração docente" (SARTI, 2009, p. 134, grifos da autora) possibilitando aos futuros professores um encontro acompanhado no 'mundo das práticas', apoiando-os inclusive no enfrentamento do já referido "choque da realidade" (VEENMAN, 1988).

Nesse mesmo sentido, Benites, Sarti e Souza Neto (2015, p. 105 e 106) ressaltam a importância do papel a ser desempenhado por professores experientes na iniciação de novos professores durante os estágios, como "experts na docência, com competências e habilidades específicas ligadas ao ensino" (grifo dos autores), cabendo-thes "[...] inserir o futuro profissional no contexto de trabalho na escola para que experimente o lugar docente [...]", de modo a thes oferecer "uma multiplicidade de referências que possibilitem sua socialização profissional [...]". Os pesquisadores advertem que, em que pesem as potencialidades formativas presentes na atuação de professores experientes na formação das novas gerações docentes, a mesma costuma ainda ser assumida como "[...] algo opcional e esporádico no trabalho docente [...]" (p. 106), revelando fragilidades relativas às relações comumente estabelecidas entre universidade e escolas, bem como ao lugar de pouco poder que, segundo Sarti (20 1 2), os professores ocupam no espaço da formação docente. 
Relação intergeracional e aprendizagem docente: elementos para rediscutir a formação de professores

As reflexões reunidas no presente artigo têm em vista oferecer subsídios para a discussão de aspectos relativos à aprendizagem docente, compreendida como processo de socialização profissional. Para tanto, busca explicitar possibilidades formativas que podem se mostrar presentes nas relações intergeracionais estabelecidas no interior da profissão docente, no caso entre professores experientes no magistério e estagiários do curso de Pedagogia. Partindo do conceito de geração proposto por Mannheim (1982), consideramos que no interior do magistério convivem diferentes unidades de geração docentes que "[...] encerram maneiras específicas de considerar a docência e de conceber as práticas, os discursos e os valores que são mais apropriados ao ensino (algo que varia conforme o momento histórico vivido)" (SARTI, 2009, p. 139). Assim:

Para além das diferenças etárias, esses professores trazem consigo modos por vezes diversos de conceber o ensino, a aprendizagem, os alunos, a escola, as relações pedagógicas, entre outros tantos fatores implicados na docência. Revelam, em maior ou menor grau, marcas das gerações de professores às quais pertencem, que se distinguem em função dos contextos históricos e sociais nos quais os sujeitos foram iniciados no magistério (SARTI, 2009, p. 139).

Sob essa perspectiva, a formação é entendida como processo de socialização (SOREL, 2005), no âmbito da qual as relações estabelecidas entre diferentes gerações docentes podem ser assumidas como "[...] recurso para a iniciação de novos professores em valores, representações, saberes e fazeres que constituem a cultura pedagógica" (SARTI, 2013 b, p. 93, grifo da autora).

Tendo em vista tal pressuposto central, que incide sobre o valor formativo das relações intergeracionais na formação profissional docente, algumas questões assumem relevância: de que forma diferentes gerações de professores se aproximam das situações de ensino, que preocupações orientam suas ações? Que significados tais situações e as ações então realizadas pelos sujeitos assumem para essas diferentes gerações? $\mathrm{E}$, ainda: que aspectos relativos à docência são evidenciados no encontro entre professores experientes no magistério e professores em processos de iniciação? Tais encontros podem amenizar, para os iniciantes, as dificuldades comumente presentes nas primeiras incursões na docência? 
Essas questões orientaram uma investigação qualitativa (BUENO, $2016)^{\prime}$ que buscou compreender as relações estabelecidas entre uma professora experiente no magistério e uma estagiária do curso de Pedagogia durante o estágio supervisionado de prática de ensino. A pesquisa foi realizada por meio de observações participantes, entrevistas semi-estruturadas, videogravações e entrevistas de videoconfrontação. Do ponto de vista conceitual, algumas categorias teóricas relacionadas à aprendizagem e ao desenvolvimento profissional docente, mais especificamente no que se refere ao pensamento do professor, mostraram-se fundamentais: as preocupações (FULLER, 1970; GAULKE, 2013 ); as dificuldades (VEENMAN, 1984) e o saber-fazer (DREYFUS; DREYFUS, 1986) que, como ressaltam Eraut (1996) e Day (2001), são elementos constitutivos do conhecimento profissional docente (SHULMAN, 1986; PASTRÉ; MAYEN; VERGNAUD, 2006). Dados e análises resultantes da referida pesquisa constituem base para a discussão proposta no presente artigo.

\section{Preocupações, dificuldades e saberfazer dos professores nos processos de aprendizagem docente}

estágio supervisionado constitui um importante recurso de iniciação pré-profissional para os futuros professores. No entanto, vários autores (VEENMAN, 1984; VONK, 1983; VALLI, 1992; LIMA; CORSI; MARIANO; PIZZO; ROCHA; SILVEIRA, 2007; GUARNIERI, 1996) ressaltam que contatos inaugurais (como é o caso do estágio) com a prática docente podem ser marcados por dificuldades diversas, relativas à falta de repertório ligados à ação por parte dos iniciantes. Day (2001, p. 86) explica que essas primeiras incursões na docência podem ser reveladoras quanto às "[...] dificuldades inevitáveis do ensino [...]" e as possíveis frustrações que as acompanham, por ser um processo de assimilação de uma realidade complexa (VEENMAN, 1984).

De acordo com Veenman (1984), as principais dificuldades enfrentadas por professores iniciantes costumam ser: manter a disciplina em sala de aula, trabalhar com a motivação dos estudantes e avaliar seus trabalhos; organizar o trabalho em sala de aula e os materiais adequados aos objetivos pedagógicos; além de lidar com problemas e ritmos individuais dos alunos e com seus pais. Além dessas dificuldades, outras são referidas: lidar com os conteúdos a ensinar (VONK, 1983; VALLI, 1992); imitar acriticamente condutas de outros professores e/ou desenvolver de uma concepção técnica do 
Relação intergeracional e aprendizagem docente: elementos para rediscutir a formação de professores

ensino (VALLI, 1992), isolar-se ou sentir-se abandonado (VALLI, 1992; LIMA; CORSI; MARIANO; PIZZO; ROCHA; SILVEIRA, 2007); e relacionar-se com os demais professores (GUARNIERI, 1996). Trata-se, portanto, de dificuldades bastante variadas, que dizem respeito a diferentes dimensões da docência.

Cabe ressaltar que, no enfrentamento dessas múltiplas dificuldades, os iniciantes na docência são orientados por uma certa perspectiva sobre o trabalho a ser realizado, marcada por preocupações específicas relativas ao ensino (FULLER, 1970; DAY, 200 1). Para Marcelo (1999, p. 61), "[...] uma preocupação seria a representação constituída por sentimentos, inquietações, pensamentos e considerações por uma questão particular ou uma tarefa". $\bigcirc$ autor esclarece que existem distinções na percepção de cada professor sobre a situação de ensino, relativas ao esquema de desenvolvimento de cada um. Fuller (1970 apud DAY, 2001 ) estabelece seis fases concernentes às preocupações iniciais dos professores, que estão intrinsecamente relacionadas ao estágio de habilidades a ser desenvolvida no exercício da profissão:

[...] preocupações consigo próprios, expectativas e aceitação profissional, adequação pessoal ao ensino, relação com os alunos, preocupação com a aprendizagem dos alunos com base no que foi ensinado, preocupações relativas às necessidades de aprendizagem dos alunos, para preocupações relativas ao contributo pessoal dos próprios professores no sentido da mudança dos alunos (DAY, 2001, p. 88).

Marcelo (1999, p. 61) esclarece que os professores assumem preocupações distintas, em função de seu nível de desenvolvimento profissional. A esse respeito, o pesquisador espanhol identificou três etapas de preocupações pelas quais os professores passam durante a carreira docente: "[...] preocupações sobre si mesmo, sobre as tarefas e sobre os alunos". Suas proposições afinam-se às ideias de Gaulke (2013, p. 19) que, por meio de uma revisão da literatura sobre as teorias das preocupações, identificou que "as preocupações dos estudantes-professores relacionadas ao ensino são: a preocupação com o eu, com a tarefa e com o impacto na aprendizagem dos alunos". As preocupações relativas ao "eu" são referentes ao estágio de "sobrevivência" no qual se encontram os iniciantes e se referem à disciplina na gestão da aula, aos ajustes pessoais e institucionais e, ainda, às características pessoais do iniciante. A esse respeito, a autora esclarece: 
A preocupação com a tarefa é relacionada a questões do momento da aula (gerenciamento de tarefas), com a assimilação do conhecimento pedagógico ou diretamente ligado à 'logística de ensino' - a gestão e organização de meios e materiais para o ensino. Já a preocupação com o impacto na aprendizagem dos alunos representa preocupações com motivação, diferenças individuais nos alunos e conquista e realização dos alunos (GAULKE, 2013, p. 191.

Gaulke (2013, p. 19) explica que a primeira fase relativa às preocupações docentes refere-se ao bem-estar dos professores; a segunda diz respeito às competências pedagógicas, bem como ao domínio de conteúdo; enquanto somente a terceira fase estaria mais diretamente voltada para a aprendizagem dos alunos. A pesquisadora ressalta a importância formativa da vivência de preocupações relativas ao ensino por parte dos iniciantes, ainda durante o período de formação inicial. Para tanto, os futuros professores devem ser expostos a "contexto de ensino da vida real", nos quais "[...] os níveis de preocupações tendem a ser elevados".

Além das preocupações e dificuldades, outro elemento que se modifica ao longo do processo de desenvolvimento profissional dos professores é o saber-fazer. A esse respeito, Dreyfus e Dreyfus (1986) propuseram um modelo organizado em cinco níveis do saber-fazer profissional, tendo em vista a capacidade do professor para lidar com as situações de ensino. Segundo tal modelo, o professor pode ser considerado como: 1. principiante, com adesão rígida a regra ou planos aprendidos, fraca percepção da situação, e ausência de juízo discricionário; 2. principiante avançado, cuja ação tende a ser baseada em atributos ou aspectos específicos, percepção limitada sobre as situações de ensino e sem possibilidades de integrar e hierarquizar os atributos e aspectos identificados; 3. competente, que lida bem com a existência de muitos alunos e considera suas ações a partir de objetivos de longo prazo, sendo capaz de realizar planificações deliberadas e conscientes, baseando-se em procedimentos estandartizados; 4. proficiente, capaz de distinguir o que é mais importante numa situação e os desvios do padrão normal, assumindo de modo menos trabalhosa a tomada de decisões e se orientando por meio de máximas, cujo o significado varia de acordo com a situação, sendo capaz de visualizar as situações de uma forma holística; e, por fim, 5. perito, que não mais se baseia em regras, princípios gerais ou máximas, compreendendo intuitivamente as 
Relação intergeracional e aprendizagem docente: elementos para rediscutir a formação de professores

situações põe meio de um entendimento tácito profundo, empregando abordagens analíticas apenas em situações novas ou problemáticas, antevendo o que é possível em cada situação.

A partir de uma apreciação crítica a respeito desse modelo proposto por Dreyfus e Dreyfus, Day (2001) ressalta a importância de considerar que as etapas vividas pelos professores são interativas e sobrepostas, constituindo processos não lineares que marcam o desenvolvimento profissional docente. Assim, apoiando-se em Eraut (1996), Day (2001), explica que o conhecimento profissional docente está estruturado em duas dimensões: uma vertical e outra horizontal. A dimensão vertical estaria relacionada ao contexto em que o conhecimento é empregado (conhecimentos: da sala de aula, seus alunos, gestão de classe e outros papéis profissionais), enquanto a dimensão horizontal assinalaria os diferentes tipos de conhecimento que são utilizados na ação docente relativos à matéria a ser ensinada e aos conhecimentos (educacional, situacional e social) em que o professor se vale de suas experiências vividas em situações semelhantes, para interpretar e solucionar as situações vivenciadas em sala de aula.

Em estudo pioneiro sobre o conhecimento dos professores, Shulman 234 (1986) ressalta a complexidade que envolve a docência, cujo enfrentamento requer uma base de conhecimentos que permita aos professores se adaptarem durante a ação, atendendo às especificidades de cada situação. $\bigcirc$ autor considera que o conhecimento estratégico docente é imprescindível para auxiliar o trabalho do professor durante situações de aula ou problemas e afirma que os elementos que o compõem são de ordem teórica, prática e moral. Esse tipo de conhecimento, para Shulman, seria inacessível aos iniciantes. Trata-se de conhecimentos relativos ao "polo do trabalho não codificado", segundo expressão de Tardif e Lessard (2012, p. 41), relativos a "[...] componentes informais da atividade, aqueles aspectos que estão implícitos ou 'invisíveis' no ofício e suas inúmeras contingências, imprevistos, ou seja, as áreas flutuantes que revelam sua complexidade".

A existência de uma dimensão não codificada ou formalizada em prescrições relativas ao ensino é prevista em trabalhos que se orientam pela didática profissional, tal como descrita por Pastré, Mayen e Vergnaud (2006). A partir dos conceitos de esquema e de invariante operatória, esses autores compreendem que a atividade efetivamente realizada pelos sujeitos durante a ação profissional transborda a tarefa inicialmente proposta. Sob 
tal perspectiva, o desenvolvimento do trabalho real envolve uma dimensão cognitiva que se faz presente nas atividades a serem realizadas pelos sujeitos, que se orientam por diferentes percepções (OCHANINE, 1981, apud PASTRÉ; MAYEN; VERGNAUD, 2006) sobre a situação. Tais percepções podem estar ligadas a imagens cognitivas ou operatórias, em função das experiências prévias dos sujeitos. Enquanto imagens cognitivas da situação constituem representações desenvolvidas independentemente de qualquer ação, as imagens de ordem operatória permitem ao sujeito a identificação de propriedades mais diretamente úteis à ação, basenado-se em representações mais específicas, elaboradas em situação.

Partindo de tais considerações, Pastré, Mayen e Vergnaud (2006) discutem a epistemologia da ação ligada à atividade profissional, destacando duas formas complementares de conhecimento cognitivo: a operatória e a predicativa. Os autores afirmam que essas duas formas (predicativa e operatória) estão enraizadas na mesma estrutura cognitiva, diferente do que afirmava Ochanine (1981), que estabelece uma diferença entre o conhecimento cognitivo e operatório. Para eles, a forma predicativa do conhecimento profissional permite aos sujeitos identificar as propriedades e as relações entre os objetos (nível de pensamento teórico sobre a situação), enquanto a forma operatória é elaborada a partir de situações reais, que irão permitir uma boa adaptação da ação (nível de pensamento pragmático). A forma operatória do conhecimento é denominada pelos autores como "inteligência das situações", resultando de processos de assimilação e de acomodação (como descritos por Piaget) vividos pelos sujeitos.

As perspectivas teóricas acima reunidas nos permitem explorar processos relativos à aprendizagem e ao desenvolvimento de professores pertencentes a diferentes gerações profissionais e que vivenciam diferentes momentos da carreira docente. No caso da pesquisa aqui referida, tais categorias nos possibilitaram discutir dados relativos ao encontro intergeracional estabelecido entre uma estagiária do curso de Pedagogia e a professora experiente que a acolheu no estágio supervisionado de prática de ensino. Processos relativos à coleta e análise dos dados desta pesquisa serão apresentados a seguir. 
Relação intergeracional e aprendizagem docente: elementos para rediscutir a formação de professores

\section{Decisões e procedimentos metodológicos}

A seleção dos sujeitos participantes da pesquisa foi baseada em alguns critérios previamente estabelecidos. No que se refere à professora, considerou-se como critério suas possibilidades de estabilidade profissional. Assim, orientando-se pelo conceito de ciclos vitais docentes (HUBERMAN, 1992; MARCELO, 1999) optou-se por selecionar professores que estivessem há mais de sete anos no magistério e, portanto, que reunissem maiores chances de já terem vivenciado a fase de estabilização profissional (entre quatro e seis anos na docência, segundo Huberman, 1992). Os professores selecionados deveriam, ainda, ter mais de 28 anos de idade que, de acordo com classificação proposta por Marcelo (1999), marca a passagem para uma fase marcada por sentimento de maior segurança na vida adulta e, por conseguinte, nas atividades docentes. Com relação ao estagiário, o único critério de seleção referia-se a sua inexperiência no magistério. Procurava-se, por meio de tais critérios, constituir uma dupla em que os sujeitos pertencessem de fato a diferentes gerações profissionais.

Seguindo esses critérios então estabelecidos, foi selecionada uma 236 professora experiente que, à época em que os dados foram reunidos (em sua sala de primeiro ano), atuava há 27 anos no magistério. As observações realizadas em classe e os dados reunidos por meio das entrevistas indicam que a professora apresentava traços próximos aos que Dreyfus e Dreyfus (1 986) associaram ao professor perito. Já a estagiária, em acordo ao critério estabelecido, não tinha nenhuma experiência na docência, era uma principiante (DREYFUS; DREYFUS, 1986), e aquele foi o primeiro estágio realizado no curso.

estágio proposto pela universidade, de "prática acompanhada" (SARTI, $2013 a$ ) previa que professora e estagiária deveriam estabelecer uma parceria em torno da docência, o que pressupunha a realização conjunta do planejamento das aulas, das atividades junto aos alunos, de momentos de reflexão e avaliação do trabalho etc. Nesse sentido, era previsto que a estagiária viveria momentos de regência das aulas, sob a supervisão da professora. As ações da estagiária e da professora em tais momentos constituíram foco para a coleta de dados durante as aulas.

Além da observação de sete aulas com seu registro em vídeo (no período de um mês), os dados foram reunidos por meio de entrevistas semi-estruturadas e entrevistas de confrontação, nas quais utilizou-se as videogravações 
das aulas (sessões de videoconfrontação). Tais sessões de videoconfrontação foram realizadas individualmente, em sete encontros com cada uma das participantes e, para cada uma dessas sessões, foram empregados episódios (cada um com duração entre dois a seis minutos) relativos a uma mesma aula registrada. Cada sessão de videoconfrontação estendeu-se por aproximadamente uma hora, resultando no total quatorze sessões/horas de entrevistas. Cada participante foi confrontada com vinte e três episódios. Durante as sessões de videoconfrontação realizadas com cada uma das participantes, foi-thes solicitado que comentassem o que thes chamava atenção em cada episódio. Ademais, no decorrer das entrevistas, a pesquisadora realizava intervenções com o objetivo de chamar a atenção das entrevistadas para certos momentos da aula, considerados especialmente interessantes no que se refere a decisões e ações assumidas pela estagiária (para cada uma das aulas selecionadas foi elaborada uma descrição, síntese sobre o conteúdo dos episódios e indicação prévia de questões a serem feitas às participantes durante a videoconfrontação).

Esse recurso metodológico permitiu-nos ter acesso a descrições e explicações elaboradas por cada uma das participantes, que explicitavam em seus depoimentos as relações estabelecidas durante as interações. Tal como previsto por Sadalla (1 997) e Larocca (2002), a confrontação com suas imagens permitiu-lhes explicar suas ações nas situações em questão, identificando elementos presentes em suas tomadas de decisão. Os dados reunidos por meio desse trabalho de campo foram analisados no que se refere ao seu conteúdo buscando, por meio do exame textual dos depoimentos reunidos durante as entrevistas semi-estruturadas e de confrontação, realizar processos de categorização (classificação e agregação), de inferência e de interpretação (BARDIN, 1979).

\section{Sobre a aprendizagem e o desenvolvimento profissional docente: o que os dados reunidos nos permitem afirmar}

De acordo com os depoimentos reunidos durante as sessões de videoconfrontação, a estagiária sentia-se autocentrada durante as aulas. Suas preocupações relacionavam-se sobretudo consigo mesma: preocupava-se em não "se perder" durante a interação com os alunos, seguindo rigidamente o 
Relação intergeracional e aprendizagem docente: elementos para rediscutir a formação de professores

roteiro pré-estabelecido, para cumpri-lo. Em alguns momentos registrados, a professora interveio na aula, solicitando alterações na atitude da estagiária.

A centralidade que a estagiária conferia ao cumprimento do roteiro de aula pré-estabelecido, mesmo que em detrimentos dos objetivos didáticos-pedagógicos em questão, foi evidenciada por ela própria e pela professora em diversos momentos das sessões de videoconforntação. A primeira aula registrada caracterizou-se sobremaneira por esse autocentramento da estagiária e demandou da professora algumas intervenções, por meio das quais ela lhe solicitava maior atenção às necessidades dos alunos. Naquela aula, a atividade proposta às crianças referia-se à elaboração coletiva de um esquema que representava a "pirâmide alimentar". Enquanto a estagiária falava aos alunos sobre os alimentos que compõem tal "pirâmide", várias crianças levantavam a mão, pedindo a palavra (como combinado inicialmente pela professora). A estagiária não as atendia e seguia com as explicações sobre o conteúdo. Em um certo momento da aula, a professora interveio, solicitando-lhe que atentasse para os alunos que pediam a palavra. Durante a entrevista, ao se confrontar com um momento daquela aula, a estagiária comentou:

Me ver falando e ninguém prestava atenção. (Risos). Eu acho que me preocupei tanto em falar, falar, falar e falar que não consegui enxergar as crianças, quem estava com a mão levantada, quem não estava, sei lá, acho que fiquei tão nervosa que não olhava, não conseguia enxergar nada, só queria falar, falar, falar, falar (ESTAGIÁRIA, 2014).

A professora, ao ser confrontada com aquele mesmo momento da aula e ao ser questionada sobre qual tinha sido seu objetivo ao solicitar à estagiária que atendesse aos alunos que estavam com os braços levantados, explicou:

Para colaborar, para que o assunto que ela estava tratando fosse visto e escutado melhor pelos alunos né. Porque senão, você fala por falar e não adianta [...] (PROFESSORA, 2014).

A professora buscava, com sua intervenção, que a ação da estagiária enfim se dirigisse aos alunos, que ela os incluísse na aula para que, assim, fosse de fato escutada por eles. Com sua intervenção, a professora apontava-lhe para a dimensão interativa da aula. A inclusão dos alunos no desenvolvimento 
das aulas regidas pela estagiária pautou outras intervenções assumidas pela professora. Um dos episódios explorados nas sessões de videoconfrontação refere-se à atividade - muito comumente realizada - de germinação do feijão no potinho com algodão. A estagiária conduziu as crianças ao pátio da escola para molhar o algodão no qual o feijão havia sido "plantado". Em fila, diante de uma torneira, as crianças entregaram o pote com o feijão para que a estagiária colocasse água. Após alguns minutos, a professora interveio aconselhando-the a deixar que os próprios alunos regassem o feijão. Durante a sessão de videoconfrontação, a professora comentou:

[...] precisava porque senão ela iria continuar colocando a água e eles não iam perceber a quantidade de água que era necessária para o potinho. Então porque assim, quando você faz uma coisa a fixação é diferente quando você só olha. A criança tem que botar a mão para poder aprender (PROFESSORA, 2014).

Enquanto a professora enfatizava as necessidades pedagógicas dos alunos na situação, a estagiária preocupava-se com o cumprimento da tarefa:

Essa parte foi a que a gente foi molhar. Primeiro eu não tinha nem pensado das crianças colocarem a água...elas mesmas colocarem a água no copinho, eu falei 'eu vou fazer porque é mais prático, mais fácil, mais rápido', e também nem tinha pensado em elas fazerem, e quando a professora me deu o toque, é verdade só que faltavam poucas crianças e aí nas próximas vezes que a gente molhou, cada um colocava água no seu, porque como a professora disse "eles precisam fazer a atividade", tipo colocar a mão, porque aí nunca mais eles esquecem (ESTAGIÁRIA, 2014).

Durante a ação, a estagiária parecia encontrar dificuldades para assumir a dimensão pedagógica da atividade, que acabava por ser assumida como um fim em si mesma. Cumpri-la no tempo estipulado era o que importava. Preocupações com relação ao tempo da aula e seu cumprimento ficaram evidentes em outros momentos registrados. Por ocasião da já referida elaboração da "pirâmide alimentar" junto aos alunos, a estagiária apresentou-hes figuras em papel que representavam alimentos de diferentes grupos. Passou então a chamar um a um os alunos para colarem as figuras na pirâmide (uma figura colada na lousa), de acordo com os grupos alimentares. Como o conteúdo já havia sido trabalho junto aos alunos, eles possivelmente teriam condições de 
Relação intergeracional e aprendizagem docente: elementos para rediscutir a formação de professores

identificar autonomamente o grupo dos alimentos. Mas a estagiária não esperava que os alunos escolhessem o grupo correspondente de cada alimento e, ao entregar a figura aos alunos chamados à frente, indicava-thes o lugar onde a mesma deveria ser colada. Ao assistir à videogravação de sua interação com a professora naquela aula, a estagiária explicou:

Para eles entenderem lógico que é melhor (deixá-los escolher o grupo de alimentos), daí você vai ver se eles sabem mesmo quais são os carboidratos ou não. Mas, eu sabia que iria demorar muito mais, e o tempo que eu tinha era bem curto; então iria ter que ser muito rápido, muito (ESTAGIÁRIA, 2014).

Para a estagiária, mais uma vez, a realização da atividade prevista no tempo estipulado assumiu lugar central entre suas preocupações, em detrimento dos fins didático-pedagógicos que thes eram relacionados. Novamente, dificuldades relativas à gestão do tempo da aula, comuns para os professores iniciantes, aliadas à preocupação em cumprir o programado caracterizaram a ação da estagiária. Como é evidenciado em seu depoimento acima transcrito, a estagiária 'sabia' que o melhor do ponto de vista didático-pedagógico 240 seria deixar que os alunos escolhessem o grupo de alimentos na atividade. No entanto, ela sabia também que tal opção demandaria um tempo mais longo de aula. A atividade dos alunos, o investimento em sua aprendizagem não 'caberia' na aula. A efetivação da atividade, como um fim em si mesma, preponderou então sobre o ensino e a aprendizagem dos alunos.

Não somente as atividades pareciam figurar como um fim em sim mesmas nas aulas regidas pela estagiária, mas também a exploração dos conteúdos junto aos alunos. Ela preocupava-se sobremaneira em 'dizer' o conteúdo:

Eu acho que o nervosismo, para não dar tempo, de ter que passar tudo, de fazer as crianças entenderem, de passar tudo que eu tinha que passar, de não dar tempo de fazer as coisas, de fazer elas ficarem quietas. Aí eu acabei não prestando atenção nelas, acabei passando tudo correndo as coisas, acho que foi isso (ESTAGIÁRIA, 2014).

A recitação do conteúdo trazia uma dimensão magistral para as aulas e uma centralidade para a figura da estagiária que, no entanto, não 
era condizente com seus sentimentos de insegurança diante dos alunos: "[...] dificuldade porque fiquei muito nervosa. Eu não sabia como as crianças iriam reagir e até a última aula foi difícil [...]" (ESTAGIÁRIA, 2014).

Para ela, o controle das crianças ("fazer elas ficarem quietas") constituía uma tarefa adicional a ser executada durante a aula, como algo isolado dos processos didáticos que a constituíam. Tratava-se de "estar com autoridade" diante da classe ou não. A autoridade perdia, em sua perspectiva, qualquer dimensão relacional e era, de certa maneira, reificada pela estagiária. Transformava-se em algo a "estar com".

Na aula em que explorou os grupos alimentares junto aos alunos, a estagiária levou algumas representações dos alimentos em plástico e outros materiais e as deixou sobre a mesa, sem explorá-las. Os alunos ficaram excitados para manipular os materiais e se dispersaram em vários momentos da aula. Outros recursos empregados foram deixados no fundo da sala, exigindo que a estagiária se deslocasse diversas vezes para buscá-los. Sobre o episódio a estagiária comentou:

[...] dá para perceber que eu não estava com autoridade, muita autoridade, não sei se é porque eu sou estagiária e não professora e tal, tem todo esse negócio. Mas, eu viro de costa, eles vão correndo mexer nas coisas (representação dos alimentos em plástico). Ah, é criança também, mas a questão mais da autoridade dentro da sala de aula, que é meio difícil quando a professora está junto, quando você não é a professora deles. Achei isso. Ah sei lá, acho que eu falo muito rápido, ou fico nervosa e não falo direito e também autoridade também né, vai muito a questão da autoridade também (ESTAGIÁRIA, 2014).

De sua parte, a professora relacionava a dispersão dos alunos durante as atividades - e à posição de fragilidade que, então, restava à estagiária - à dinâmica estabelecida em aula resultante, entre outros fatores, do modo como a mesma fora organizada. Ao comentar o mesmo episódio: "(...) uma coisa que é complicada nesse momento é ela não ter antecipado tudo que ela precisava, aí deixou livre para que todo mundo fosse à mesa (...)" (PROFESSORA, 2014).

Dificuldades por parte da estagiária em lidar com os recursos didáticos durante a aula ficaram novamente evidentes no episódio em que a "pirâmide alimentar" foi organizada. Novamente, houve dispersão entre os alunos. 
Relação intergeracional e aprendizagem docente: elementos para rediscutir a formação de professores

Quando questionada pela pesquisadora sobre suas dificuldades naquele momento, a estagiária explicou:

Nessa aula foi difícil. Dificuldade desde deixar as crianças quietas, de me organizar com as figuras, de colocar na pirâmide e de explicar; de explicar não, mas de tentar fazer com que eles falassem: 'Isso é carboidrato' e o tempo. Foi totalmente difícil essa aula (ESTAGIÁRIA, 2014).

Os recursos (figuras) aparecem então como complicadores da ação da estagiária, posto que deveriam - assim como os alunos, os objetivos didático-pedagógicos, o tempo, o espaço etc. - ser integrados à dinâmica da aula. E, ao lado desses elementos que, previstos para a aula, eram dificilmente integrados à ação pela estagiária, existiam outros que se impunham a sua ação, mesmo que ela não fosse ainda capaz de antecipá-los.

[...] eu não imaginava que elas fossem dançar. Imaginei que elas fossem ficar mais quietas, mais calmas. É aí ficou aquele alvoroço todo, a professora falou para as crianças sentarem até acabar a música, para depois dançar conforme fala a letra, e foi isso que a gente fez, foi o mais certo fazer, porque eu não tinha pensado nisso, quando planejei a aula (ESTAGIÁRIA, 2014).

Suas dificuldades para antecipar o necessário para a aula, as necessidades dos alunos e suas reações diante deles ficaram evidentes em vários momentos e foram ressaltadas nos depoimentos. A estagiária não assumia uma posição estratégica na situação, o que the impingia grande fragilidade diante dos alunos.

No entanto, tais elementos que, até o momento da ação, permaneciam imprevisíveis para a estagiária, pareciam bastante evidentes para a professora. Sobre um episódio em que a estagiária tentava, sem sucesso, organizar os alunos para aprenderem a letra de uma música sobre a alimentação, a professora comentou:

Eu me lembro desse dia, seria interessante que ela tivesse posto a música primeiro para escutar e depois dançar. Mas ela fez ao contrário, ela quis que fizesse tudo ao mesmo tempo lescutar a música e dançar). Criança não consegue fazer isso. Olha não dá para escutar a música (PROFESSORA, 2014). 
Essas dificuldades de antecipação por parte da estagiária eram acompanhadas por dificuldades para integrar os alunos, suas ações e necessidades durante as aulas. Parecia-the especialmente difícil incluir os alunos na aula, assumir a dimensão relacional do ensino (ALTET, 2000). A aula figurava-the como algo preexistente à ação. Assim como ocorria com a autoridade lque ela esperava "estar com"), a aula também era assumida como 'coisa', reificada, revelando uma perspectiva técnica da docência (VALLI, 1992). A interatividade e a dinamicidade constitutivas da aula pareciam-the inacessíveis:

No momento (da aula sobre a pirâmide alimentar) eu não conseguia enxergar outra forma de fazer; eu estava tão nervosa com a pirâmide, com as crianças, de elas virem fazer e não dá certo, de não caber, de ter que pegar isso e aquilo, que eu não conseguia ver outra forma. Eu não conseguia parar e pensar, eu não conseguia ver de outra forma [...] (ESTAGIÁRIA, 2014).

Por outro lado, a professora parecia muito mais à vontade para assumir uma perspectiva dinâmica, interativa e integrativa de aula. Sobre a mesma aula em que a pirâmide alimentar foi trabalhada:

Então o material estava pronto do jeitinho que nós tínhamos combinado. Ela iniciou de uma maneira que era para ser daquele jeito mesmo, entendeu? De ir mostrando um por um. Só que fui observado que estava demorando demais e não iria dar tempo. Tivemos que fazer uma mudança, só que com essa mudança não estava atendendo, porque as crianças estavam dispersas. E o nosso objetivo era ter a atenção delas. Então foi assim fomos tentando. (Risos). Foi uma aula de muda aqui, muda ali. E para quê? Para alcançar o objetivo (PROFESSORA, 2014).

Em seus depoimentos, a professora mostrava-se atenta a certos 'pontos cegos' existentes na ação da estagiária, relativos: à participação e atenção dos alunos na aula; à organização e ao tipo de material escolhido; à clareza da linguagem e ao modo de se dirigir aos alunos; ao envolvimento do coletivo da turma na aula; e aos fins didático-pedagógicos das atividades. Durante as sessões de videoconfrontação, tais elementos que se encontravam fora do campo de visão da estagiária foram evidenciados em seus depoimentos. Sobre as figuras trazidas pela estagiária para representar os alimentos dos diferentes grupos da pirâmide alimentar: 
Relação intergeracional e aprendizagem docente: elementos para rediscutir a formação de professores

E mais assim imagens maiores, [...] o peixe, é claro que ela não ia trazer o peixe aqui, mas teria que ter desenhado um peixe grande para eles verem. São coisinhas assim para ficar mais visível, porque as figuras pequenas atrapalharam um pouco (PROFESSORA, 2014).

E, mais adiante, sobre outro episódio daquela mesma aula, referente à organização dos recursos didáticos:

Então teve um momento que estava tudo bagunçado, muito misturado, e eu pedi para ela, "Vamos separar". Aí nós demos uma paradinha, ela parou de falar e aí ela organizou todas as frutas de um lado, os carboidratos, as proteínas né. Assim fica confuso, a gente sabe que é tudo importante, mas ela não estava separando. Precisava ter separado (PROFESSORA, 2014).

Mas de todos os elementos evidenciados pela professora, os que mais pareciam the chamar atenção eram os relacionados ao envolvimento dos alunos na aula:

Marcos falou, falou, falou um monte de coisa, a sala toda ficou numa maior bagunça porque (a estagiária) não estava escutando, e ela não retomou o que ele tinha falado [...] você tem que depois retomar e falar para classe o que ele falou... (PROFESSORA, $2014)$.

$[\ldots]$

É importante que a criança fale, para ver se está prestando atenção naquilo que está sendo colocado, e para ver a opinião deles sobre o assunto (PROFESSORA, 2014).

$[\ldots]$

Então, nesse momento eu não deixaria sair (o aluno), porque eu estou explicando e nesse momento não sai, depois pode ir ao banheiro. Quando você está explicando alguma coisa a criança não sai da sala, então isso é uma coisa importante, ela tem que prestar atenção naquilo que se está explicando (PROFESSORA, $2014)$.

[...]

Essa coisa de individual e coletivo, individual e coletivo, individual e coletivo, tem que ter isso. Se você não tiver isso, você perde o controle da classe (PROFESSORA, 2014).

$[\ldots]$

É o envolvimento da turma tem que ter, e não pode dar as costas para o grupo, é tentar envolvê-los (PROFESSORA, 2014). 
As preocupações mais centrais da professora na situação de ensino pareciam, pois, voltadas ao envolvimento de todos os alunos nas atividades propostas, considerado por ela como condição central para a realização da aula. Em posição estratégia diante da situação, em busca das condições de sua efetivação, a professora procurava lesperando que a estagiária assim também o fizesse) antecipar, perceber e atender as necessidades pedagógicas dos alunos durante as atividades. Para tanto, suas decisões pautavam-se em uma perspectiva capaz de integrar as intervenções das crianças, os recursos didáticos, os conteúdos previstos e já trabalhados, bem como as dimensões espaciais e temporais da aula. Essa perspectiva integrativa presente no modo como a professora aproximava-se do ensino - aparentemente inacessível à estagiária naquele momento - parece ligada a uma "inteligência das situações" (PASTRÉ; MAYEN; VERGNAUD, 2006) e remete-nos a discussões sobre o saber-fazer docente (DREYFUS; DREYFUS, 1986) e seu processo de aprendizagem.

\section{À guia de conclusão: saber-fazer, conhecimento operatório e desenvolvimento profissional docente}

Tal como pode ser depreendido dos dados aqui apresentados, a estagiária parecia pautar suas ações e decisões em imagens fragmentadas das situações vividas, nas quais os diferentes desafios a serem enfrentados eram assumidos isoladamente: o "controle" dos alunos, a transmissão dos conteúdos, a gestão do tempo, a atenção às demandas e inteervenções dos alunos, a necessidade de "estar com autoridade" e de controlar suas próprias emoções etc. A gestão de todas esses desafio, assim isoladamente, demandava enorme despêndio de energia de sua parte. Uma visão mais abrangente das situações era-lhe inacessível no momento e contemplar um dos muitos elementos envolvidos significava, para ela, excluir tantos outros do campo de visão. A docência parecia-lhe, portanto, uma tarefa excessivamente árdua, a qual era necessário sobreviver, nos termos de Veenman (1984). Durante uma das entrevistas, aparentemente exausta, ela destacou: "[...] até a última aula foi difícil, todas as aulas foram difíceis!"

De sua parte, a professora era capaz de manter uma posição mais estratégica nas situações de ensino, preocupando-se com aspectos que thes eram mais centrais (sobretudo o envolvimento dos alunos) e identificando 
Relação intergeracional e aprendizagem docente: elementos para rediscutir a formação de professores

propriedades que, ali presentes, mostravam-se mais diretamente pertinentes à ação. Assim, enquanto a estagiária alcançava apenas com imagens cognitivas das situações, a professora contava com uma perspectiva operatória para se aproximar das mesmas, sendo capaz de elaborar, em situação, representações que thes eram mais específicas (PASTRÉ; MAYEN; VERGNAUD, 2006).

A professora parecia considerar esse seu modo de se aproximar das situações como uma vantagem conquisatada profissionalmente, que the possibilitava acesso ao que Tardif e Lessard (2012) denominam "polo do trabalho não codificado". Nessa direção, a professora explicou: "[...] são alguns detathes que a gente só vai adquirindo com o tempo, se você tiver entendido que a participação da criança é muito importante, você vai deixar todos os momentos ela participar [...]" (PROFESSORA, 2014). E, em outro momento, ela acrescenta:

[...] detalhes que a gente só vai adquirir no dia a dia. No dia a dia, você pode ter um monte de teorias, as técnicas, as coisas; mas você vai ver até onde funciona na hora em que você estiver lá. Às vezes você faz de um jeito e não dá certo; naquele dia deu certo, no outro dia não vai dar (PROFESSORA, 2014).

A percepção e antecipação de tais "detalhes" ligados à ação consistia pois, para a professora, uma prerrogativa docente, ligada a um saber-fazer profissional desenvolvido ao longo da carreira (DREYFUS; DREYFUS, 1986). Tais "detalhes", ocultos ou invisíveis para os iniciantes, eram-lhes acessíveis em função da perspectiva operatória que marcava suas aproximações com as situações de aula. Pautando-se, então, em conhecimentos de tipo operatório (PASTRÉ; MAYEN; VERGNAUD, 2006) era capaz de antecipar a reação dos alunos e investia-se na resolução de problemas e no replanejamento das ações.

Para a estagiária, presa a uma perspectiva predicativa sobre o ensino (PASTRÉ; MAYEN; VERGNAUD, 2006) - marcada por "saberes proposicionais" (AZANHA, 1987, p.74), que precedem a atividade - a percepção das situações tendia a ser fragmentada, oferecendo-lhe poucos recursos para decisões. $\bigcirc$ acesso que teve, em alguns momentos, a uma percepção mais específica das situações foi-the possibilitado pelas intervenções realizadas pela professora durante a aula. De acordo com os depoimentos reunidos, a relação de parceria estabelecida com a professora possibilitou-lhe identificar limites em suas 
percepções acerca das situações de ensino, bem como nas decisões então assumidas.

[...] não consegui enxergar as crianças, quem estava com a mão levantada [...]. É, a professora deu uma baita chamada de atenção, mas valeu apena..., a partir daí que eu comecei a prestar atenção mais se as crianças estavam com os braços levantados ou não (ESTAGIÁRIA, 2014).

$[\ldots]$

[...] ela (a professora) abriu os meus olhos para algo que eu não tinha nem pensado, que é importante que a criança... que ela faça a atividade, ela sozinha, porque depois ela nunca mais vai esquecer. E para mim, estando lá, era mais prático, mais fácil molhar lo copo com o feijão) e explicar, tirar o excesso da água e pronto, para não perder tempo (ESTAGIÁRIA, 2014).

$[\ldots]$

[...] a professora falou para a gente ... me falou para falar isso, para as crianças sentarem até acabar a música, para depois dançar conforme fala a letra, e foi isso que a gente fez, foi o mais certo fazer, porque eu não tinha pensado nisso, quando planejei a aula (ESTAGIÁRIA, 2014).

$[\ldots]$

A forma como ela (a professora) organizou os alunos melhorou, porque eles estavam pertinho de mim, dava para prestar mais atenção. Não se dispersavam com mochila, mesa, caderno (ESTAGIÁRIA, $2014)$.

A partir desses depoimentos da estagiária e das observações realizadas, podemos inferir que as intervenções realizadas pela professora durante as aulas ofereceram oportunidades de aprendizagem profissional para a estagiária que, se sozinha nas mesmas situações, não contaria com recursos para aproveitá-las do ponto de vista formativo. A presença e as intervenções da professora trouxeram-lhe possibilidades para identificar, assimilar e reconsiderar elementos presentes nas situações e em suas ações diante dos alunos ultrapassando o que poderíamos denominar como 'prática pela prática' presente no modelo atual de formação de professores (ARAUJO, 2014; DAY, 2001 ; IMBERNÓN, 2011 ; MARCELO, 1999; PASTRÉ; MAYEN; VERGNAUD, 2006; SARTI, 2009, 201 3b, 2015 l e que pode constituir um limitador para o desenvolvimento profissional docente. De acordo com DAY (2001, p. 91), a experiência precisa "[...] ser assimilada, examinada, analisada, considerada e negociada [...]"para se tornar conhecimento profissional - operatório, nos 
Relação intergeracional e aprendizagem docente: elementos para rediscutir a formação de professores

termos empregados pela didática profissional - conhecimento incorporado, acessível durante a ação. Trata-se, portanto, de uma aprendizagem realizada por meio da articulação entre a atividade produtiva e atividade construtiva, que permite desenvolver competências profissionais (PASTRÉ; MAYEN; VERGNAUD, 2006). Cabe ressaltar que a construção de conhecimentos operatórios está ligada à vivência de situações empríricas, mas é potencializada por processos reflexivos sobre a ação, que permitam ao sujeito aprender com e sobre o próprio trabalho e de fato desenvolver-se profissionalmente.

E, como indicam as discussões aqui empreendidas sobre os dados reunidos, as relações intergeracionais estabelecidas entre iniciantes e profissionais experientes assumem destacada importância para os processos de aprendizagem profissional. Por meio dos encontros intergeracionais, o profissional experiente oferece ao iniciante acesso ao "polo não codificado" (TARDIF; LESSARD, 2012 ) do trabalho, permitindo-the experimentá-lo a partir de um lugar mais estratégico e, portanto, mais próximo ao 'real'. A presença do profissional experiente nesse processo, acompanhando (SARTI, $2013 a$; SARTI; ARAÚjO, $2016)$ o iniciante na experimentação desse lugar profissional - ampliando seu campo de visão e responsabilizando-se por ele - possivelmente torna-o menos

248 suscetível aos sofrimentos que marcam o "choque da realidade" descrito por Veenman (1984).

No caso da formação de professores, tais considerações apontam para um modelo formativo cuja centralidade resida nos processos de socialização profissional docente (SARTI, 2009, 2013b) que requerem, entre outros possiveis fatores, relações mais estreitas entre a universidade e as escolas de Educação básica e um papel institucional e formativo mais bem definido para os professores experientes que recebem os iniciantes em suas classes. Trata-se de investir em um caminho que, tal como proposto por Nóvoa (2007, 2009), revolucione a formação de professores, possibilitanto que a mesma seja realizada "a partir de dentro" do magistério e assuma finalmente sua dimensão profissional.

\section{Nota}

1 Pesquisa aprovada pelo Comitê de Ética em Pesquisa em Seres Humanos do Instituto de Biociências da Universidade Estadual Paulista "Júlio de Mesquita Filho", por meio do Parecer $\mathrm{n}^{\circ}$ 626. 173. 


\section{Referências}

ALTET, Marguerite. L'analyse de pratioues: Une démarche de formation professionnalisante? Recherche et formation, Paris, n. 35, p. 25-41, 2000.

AZANHA. José Mário Pires. Educação: alguns escritos. São Paulo: Companhia Editora Nacional, 1987.

ARAÚJO, Simone Reis Palermo Machado de. Acolhimento no estágio: entre modelo e possibilidades de formação docente. 2014. 202f. Dissertação (Mestrado em Educação) Programa de Pós-Graduação em Educação do Instituto de Biociências, Universidade Estadual Paulista, Rio Claro, 2014.

BARDIN, L. Análise de conteúdo. Lisboa: 70, 1979.

BENITES, Larissa Cerignoni; SARTI, Flavia Medeiros; SOUZA NETO, Samuel de. De mestres de ensino a formadores de campo no estágio supervisionado. Cadernos de Pesquisa, São Paulo, v. 45, n. 155, p. 100-1 17, 2015. Disponível em: http://dx.doi. org/10.1590/198053142928. Acesso em: 25 fev. 2017.

BUENO, Michelle Cristina. Relações intergeracionais docentes e estágio supervisionado: um estudo sobre possibilidades e limites na formação de professores. 2016. $213 f$. Dissertação (Mestrado em Educação) - Programa de Pós-Graduação em Educação do Instituto de Biociências, Universidade Estadual Paulista, Rio Claro, 2016.

CANCHERINI, Ângela. A socialização do professor iniciante: um difícil começo. 2009. 21 lf. Dissertação (Mestrado em Educação) - Programa de Pós-Graduação Stricto em Educação, Universidade Católica de Santos, Santos, 2009.

COSTA FILHO, Roraima Alves da. Professores iniciantes de educação física: discussões a partir das fontes de autoeficácia docente. 2014. 123f. Dissertação (Mestrado em Ciências da Motricidade) - Programa de Pós- Graduação em Ciências da Motricidade, Universidade Estadual Paulista, Rio Claro, 2014.

DAY, Christopher. Desenvolvimento profissional de professores: os desafios da aprendizagem permanente. Portugal: Porto Editora, 2001.

DREYFUS, Hubert Lederer; DREYFUS, Stuart. Mind our machine: the power of human intuition and expertise in the era of the computer. New York: The Free Press. 1986. 
Relação intergeracional e aprendizagem docente: elementos para rediscutir a formação de professores

ERAUT, Michael. Developing Professional Knowledge Within a Client-Centred Orientation. In: T.R. GUSKEY and M. HUBERMAN (Eds). Professional development in education: new paradigms and practices. New York: Teachers College Press. 1996.

ESTAGIÁRIA. Entrevista. Rio Claro. São Paulo, 20 maio, 2014.

FERREIRA, Lílian Aparecida. O professor de educação física no primeiro ano da carreira: análise da aprendizagem profissional a partir da promoção de um programa de iniciação à docência. 2005. 21 6f. Tese (Doutorado em Educação) - Programa de Pós-Graduação em Educação, Universidade Federal de São Carlos, São Carlos, 2005.

FULLER, Frances. Personalized education for teachers: one application of the Teacher Concerns Model. Austin, Texas, University of Texas, Research and Development Center for Teacher Education, Austin, 1970.

GAULKE, Tamar Genz. Aprendizagem da docência de música: um estudo a partir de narrativas de professores de música da educação básica. 2013. 152f. Dissertação Mestrado em Música) - Programa de Pós-Graduação em Música, Universidade Federal do Rio Grande do Sul, Porto Alegre, 2013.

GUARNIERI, Maria Regina. Tornando-se professor: o início da carreira docente e a consolidação na profissão. 1996. 149 f. Tese (Doutorado em Educação) - Programa de Pós-Graduação em Educação, Universidade Federal de São Carlos, São Carlos, 1996.

HUBERMAN, Michaël. O ciclo de vida profissional. In: NÓvOA, António (Org.). Vida de professores. Porto: Porto Editora, 1992.

IMBERNÓN, Francisco. Formação docente e profissional. São Paulo: Cortez, 2011.

LAROCCA, Priscila. Psicologia e prática pedagógica: o processo de reflexão de uma professora. 2002. 367f. Tese (Doutorado em Educação) - Programa de Pós-Graduação em Educação, Universidade Estadual de Campinas, Campinas, 2002.

LIMA, Emília Freitas de; CORSI, Adriana Maria; MARIANO, André Luiz Sena; PIZZO, Hilda Maria Monteiro Silvia Vilhena; ROCHA, Gisele Antunes; SILVEIRA, Maria de Fátima Lopes da. Sobrevivendo ao início da carreira docente e permanecendo nela. Como? Por quê? $\bigcirc$ que dizem alguns estudos. Educação e Linguagem, São Paulo, v. 10, n. 15, p. 138-160, jan./jun. 2007.

MANNHEIN, Karl. O problema sociológico das gerações. In: FORACCHI, Marialice Mencarini (Org.). Mannheim: Sociologia. São Paulo: Ática, 1982. (Coleção Grandes Cientistas Sociais). 
MARCELO, Carlos Garcia. Formação de professores: para uma mudança educativa. Tradução Isabel Narciso. Porto: Porto Editora, 1999.

MARIANO, André Luiz Sena. A construção do início da docência: um olhar a partir das produções da ANPEd e do ENDIPE. 2006. 142f. Dissertação (Mestrado em Educação) - Programa de Pós-Graduação em Educação, Universidade Federal de São Carlos, São Carlos, 2006.

NÓVOA, António. O regresso dos professores. Lisboa: Presidência Portuguesa do Conselho da União Europeia, 2007. (Conferência de desenvolvimento profissional de professores para a qualidade e para a equidade da aprendizagem ao longo da vida).

NÓVOA, António. Para uma formação de professores construída dentro da profissão. Professores: Imagens do futuro presente. Educa: Lisboa, 2009.

OCHANINE, Selon. L'image opérative. Actes d'un séminaire (1-5 juin 1981 ) [organisé par I'] université de Paris 1 (Panthéon-Sorbonne), Centre d'éducation permanente, département d'ergonomie et d'écologie humaine; recueil d'articles de D. Ochanine. Paris: Université de Paris 1, 1981.

PASTRÉ, Pierre; MAYEN, Patrick; VERGNAUD, Gérard. La didactique professionnelle. Revue Française de Pédagogie, En Ligne, n. 154, p. 145-198, 2006.

PIAGET, Jean. La prise de conscience. Paris: PUF. 1974.

PIENTA, Ana Cristina Gipiela. Aprendendo a ser professor: dificuldades e iniciativas na construção da práxis pedagógica do professor iniciante. 2007. 13 lf. Dissertação (Mestrado em Educação) - Programa de Pós-Graduação em Educação, Pontifícia Universidade Católica do Paraná, Curitiba, 2007.

PROFESSORA. Entrevista. Rio Claro. São Paulo, 22 maio, 2014.

RODRIGUÊS, Heloiza. O peão vermelho no jogo da vida: o professor iniciante de história e a construção dos saberes docentes. 2010. 225f. Dissertação (Mestrado em Educação) - Programa de Pós-Graduação em Educação, Universidade do Vale do Rio dos Sinos, São Leopoldo, 2010.

SADALLA, Ana Maria Falcão de Aragão. Com a palavra, a professora: suas crenças, suas ações. 1997. 184 f. Tese (Doutorado em Educação) - Programa de Pós-Graduação em Educação, Universidade Estadual de Campinas, Campinas, 1997.

SARTI, Flavia Medeiros. Parceria intergeracional e formação docente. Educação em Revista, Belo Horizonte, v. 25, n. 2, p. 133-152, 2009. 
Relação intergeracional e aprendizagem docente: elementos para rediscutir a formação de professores

SARTI, Flavia Medeiros. $\bigcirc$ triângulo da formação docente: seus jogadores configurações. Educação e Pesquisa, São Paulo, v. 38, n. 2, p. 323-338, abr./jun. 2012.

SARTI, Flavia Medeiros. Pelos caminhos da universitarização: reflexões a partir da masterização dos IUFM franceses. Educação em Revista, Belo Horizonte, v. 29, n. 4, p. 215-244, dez. $2013 a$.

SARTI, Flavia Medeiros. Relações intergeracionais e alternância na formação docente: considerações a partir de uma proposta de estágio supervisionado. Cadernos de Educação UFPel, Pelotas, v. 46, p. 83-99, set./dez. 2013 b.

SARTI, Flavia Medeiros; ARAÚJO, Simone Reis Palermo Machado de. Acolhimento no estágio supervisionado: entre modelos e possibilidades para a formação docente. Educação, Porto Alegre, v. 39, n. 2, p. 175-184, maio/ago. 2016.

SOREL, Maryvonne. Préambule. In: SOREL, Maryvonne; WITTORSKI, Richard. La professionnalisation en actes et en questions. Paris: L'Harmattan, 2005.

SHULMAN, Lee. Knowledge and teaching: foundations of a new reform. Harvard Educationall Review, Cambridge, v. 57, n. 1, p. 1-22, 1986.

SIMON, Marinice Souza. Inserção de professores iniciantes no campo profissional: um estudo de caso na escola básica. 2013. 21 Of. Tese (Doutorado em Educação) - Programa de Pós-Graduação em Educação, Pontifícia Universidade Católica do Rio Grande do Sul, Porto Alegre, 2013.

SOARES, Cristiane Maria Gonçalves. A prática docente do professor iniciante. 2004. $215 f$. Dissertação (Mestrado em Educação) - Programa de Pós-Graduação em Educação, Universidade Federal de Pernambuco, Recife, 2004.

TARDIF, Maurice. Saberes docentes e formação profissional. Rio de Janeiro: Vozes, 2010.

TARDIF, Maurice; LESSARD, Claude. O trabalho docente. Elementos para uma teoria da docência como profissão de interações humanas. Petrópolis: Vozes, 2012.

VALLI, Linda. Reflective teacher education: cases and critiques. New York, State University of New York Press, 1992.

VEENMAN, Simon. Perceived problems of beginning teachers. Review of Educacional Research, [S.I.], v. 54, n. 2, p. 143-178, 1984. Disponível em: http://citeseerx.ist.psu. edu/viewdoc/download?doi=10.1 1.834.9292\&rep=rep 1 \&type=pdf. Acesso em: 3 jan. 2017. 
El proceso de llegar a ser profesor: un análisis de la formación inicial. In: VILLA, Aurelio (Coord.). Perspectivas y problemas de la función docente. Madrid: Narcea, 1988.

VONK, John. Problems of the Beginning Teacher. European Journal of the Teacher Education, London, v. 6, n. 2, p. 133-150, 1983.

Profa. Dra. Flavia Medeiros Sarti

Universidade Estadual Paulista Júlio de Mesquita Filho | UNESP

Câmpus de Rio Claro |Instituto de Biociências

Programa de Pós-Graduação em Educação Grupo de Pesquisa Docência, Formação de Professores e Trabalho Docente |

DOFPPEN

E-maillfmsarti@rc.unesp.br

Ms. Michelle Cristina Bueno

Secretaria da Educação do Município de Rio Claro | São Paulo Universidade Estadual Paulista Júlio de Mesquita Filho | UNESP

Câmpus de Rio Claro | Instituto de Biociências

Programa de Pós-Graduação em Educação

Grupo de pesquisa: Docência, Formação de Professores e Trabalho Docente |

DOFPPEN

E-mail | michellebueno772@hotmail.com

Recebido 20 mar. 2017

Aceito 10 maio 2017 